\title{
A ELABORAÇÃO DE MATERIAIS DIDÁTICO-PEDAGÓGICOS DE LÍNGUA INGLESA NA EDUCAÇÃO DE JOVENS E ADULTOS
}

\author{
Ana Claudia Cunha Salum é doutora em Linguística Aplicada e professora de língua inglesa do Colégio de Aplicação da Universidade Federal \\ de Uberlândia (CAP/UFU). \\ E-mail: anac170@yahoo.com.br \\ Alessandra Leles Rocha é graduanda do Curso de Letras - Habilitação em Língua Inglesa e bolsista no Programa de Pró-Reitoria de Graduação \\ da Universidade Federal de Uberlândia (PROGRAD/UFU). E-mail: alessandralelesrocha@ hotmail.com \\ Mariana Ruiz Nascimento é graduanda do Curso de Letras - Habilitação em Inglês e Literaturas de Língua Inglesa da Universidade Federal
} de Uberlândia e professora no Programa Idiomas sem Fronteiras (IsF). E-mail: mariruiznasci@ yahoo.com.br

\section{Resumo}

Este trabalho objetiva relatar atividades desenvolvidas durante um projeto de elaboração de materiais didático-pedagógicos para alunos da Educação de Jovens e Adultos. Tal projeto propiciou experiências linguísticas e metodológicas aplicadas ao ensino da língua inglesa para duas discentes do Curso de Letras, sob coordenação da professora de inglês do Colégio de Aplicação da Universidade Federal de Uberlândia.

\begin{abstract}
This article aims at relating activities developed during a project for elaborating didactic and pedagogic material for youth and adult education students. The project allowed linguistic and methodological experiences applied to the teaching of English for two interns from the Language Course, coordinated by the English teacher of the Application School from the Federal University of Uberlândia.
\end{abstract}

\section{Introdução}

Uma das tarefas mais importantes da prática educativo-crítica é propiciar as condições em que os educandos em suas relações uns com os outros $e$ todos com o professor ou com a professora ensaiam a experiência profunda de assumir-se. Assumir-se como ser social e histórico, como ser pensante, comunicante, transformador, criador, realizador de sonhos, capaz de ter raiva porque capaz de amar. Assumir-se como sujeito porque capaz de reconhecer-se como objeto. Paulo Freire, 1997, p.46.

O Programa de Bolsas de Graduação instituído pela Universidade Federal de Uberlândia, por meio de seus projetos, tem como principais objetivos: i) Incentivar o caráter interdisciplinar, visando a uma formação acadêmica de qualidade, ética e cidadã; ii) Estimular a melhoria do ensino da graduação por meio do desenvolvimento de novas práticas e experiências pedagógicas no âmbito do curso; iii) Desenvolver ações que procurem integrar o 
ensino, a pesquisa e a extensão e iv) Propor atividades que promovam o contato dos bolsistas e demais estudantes do curso com a realidade social em que estejam inseridos, estimulando o desenvolvimento de uma consciência do papel do estudante perante a nossa sociedade.

O presente trabalho é um relato de experiência das atividades desenvolvidas durante um dos projetos do Programa de Bolsas de Graduação, realizado no Colégio de Aplicação da Universidade Federal de Uberlândia por duas discentes do Curso de Letras, sob coordenação de uma professora de língua inglesa do referido Colégio. O objetivo principal do Projeto consistiu em elaborar material didático para o curso básico e profissionalizante de jovens e adultos.

O projeto, que se desenvolveu no interstício de 2015 e 2016, visou abrir espaço para as professoras em formação aprimorarem seus conhecimentos, competências e práticas pedagógicas relativas ao ensino e aprendizagem de língua inglesa, a partir da elaboração de materiais didáticos e de planejamentos de aulas e do curso em consonância com esses materiais. Concomitantemente, o projeto proporcionou espaço para o estudo, reflexão, discussão e prática do exercício da docência em inglês, uma vez que os materiais elaborados foram aplicados e avaliados, resultando em conhecimento para as graduandas no que se refere às especificidades dessa modalidade de ensino e dos estudantes jovens, adultos e idosos que dela participam.

As alunas em formação, por meio do projeto intitulado "Elaboração de materiais didáticos e pedagógicos para a educação de jovens e adultos: escolarização e trabalho na era digital" puderam vivenciar experiências linguísticas e metodológicas aplicadas ao ensino da língua inglesa destinado à educação de jovens e adultos. Dessa forma, o projeto estimulou a melhoria e a qualidade do processo de formação dessas discentes, à medida que promoveu a integração entre a sua formação acadêmica e a sua futura atividade profissional.

O projeto incluiu a elaboração de materiais que contemplavam o uso de tecnologias de informação e comunicação para o ensino da língua inglesa, assim como o planejamento de aulas e do curso que se baseou nesses materiais didáticos e pedagógicos confeccionados. A confecção de materiais de suporte pedagógico, que serviram de direcionamento para o planejamento das aulas e do curso da modalidade Educação de Jovens e Adultos, contemplou a proposição de que língua inglesa e tecnologia, principalmente a internet, fossem trabalhadas como linguagens de acesso à informação e à inclusão social no mundo globalizado (FINARDI; PREBIANCA; MOMM, 2013). Ademais, partindo de uma perspectiva discursiva, buscou-se elaborar materiais que permitiram explorar os componentes culturais e ideológicos que permeiam as aulas de Língua Estrangeira (LE), sobretudo os textos e temas que compõem a ementa do curso de língua inglesa destinados à modalidade de educação de jovens e adultos, já que, acredita-se, língua, cultura e ideologia se constituem mutuamente.

\section{1) A importância da Educação de Jovens e Adultos para a sociedade brasileira}


A Educação de Jovens e Adultos (EJA) constitui um dos grandes desafios a ser enfrentado pela sociedade brasileira. Dentre os fatores que corroboram a emergência desse enfrentamento estão as mudanças socioeconômicas e os avanços tecnológicos ocorridos nos últimos anos, os quais, associados aos processos de mecanização e automação aplicados nos diversos setores produtivos, têm contribuído sobremaneira para o fechamento de vários postos de trabalho, especialmente no setor primário, que emprega uma parcela significativa da população com menor nível de escolaridade e baixa qualificação profissional.

A Constituição Federal de 1988 estendeu a todos os cidadãos brasileiros o direito ao Ensino Fundamental, independente da faixa etária, visando ampliar as oportunidades educacionais àqueles que ultrapassaram a idade prevista no ensino regular de escolarização. Nesse mesmo sentido, a Lei de Diretrizes e Bases (LDB) aponta, no artigo 37, que a educação de jovens e adultos é destinada àqueles que não tiveram acesso ou continuidade de estudos no ensino fundamental e médio no tempo oportuno (BRASIL, 1996).

Nas últimas décadas, a legislação educacional tem dado especial importância ao desenvolvimento de projetos de ensino, pesquisa e extensão que priorizem essa modalidade de ensino, como se pode constatar pelo fato de os Institutos Federais incorporarem a EJA em suas políticas de educação profissional, técnica e tecnológica, de forma integrada, concomitante ou subsequente. Trata-se de uma oferta que visa reparar e restaurar o direito a uma escola de qualidade a uma parcela significativa da população brasileira, assim como o reconhecimento de igualdade ontológica de todo e qualquer ser humano.

Há de se destacar, também, que uma educação profissional e tecnológica passa a ser considerada uma ação estratégica para o desenvolvimento da sociedade, atendendo a diferentes públicos, promovendo a inclusão social de indivíduos que se encontram em vulnerabilidade social (SILVA et. al., 2012).

Buscando contribuir com a proposição de um projeto pedagógico que possa vir a ser multiplicado em outras escolas, uma vez que o Colégio de Aplicação da Universidade Federal de Uberlândia é um campo de referência com experiências que repercutem na cidade e região, estabeleceu-se uma parceria entre esse colégio e o Instituto Federal do Triângulo Mineiro (IFTM), de modo a contribuir para o retorno, a permanência e a conclusão de curso por jovens, adultos e idosos, por meio de um projeto orientado pela ressignificação dos conhecimentos, pelo estreito diálogo desse estudante em defasagem escolar com a dinâmica da vida, a cultura, a sociedade digital e o trabalho.

Essa parceria fundamenta-se na publicação do documento base PROEJA Formação Inicial e Continuada - Ensino Fundamental - PROEJA/FIC/Ensino Fundamental (BRASIL, 2007) que propõe a formação profissional aliada à escolarização, tendo como princípio a formação integral que propicie ao estudante jovem, adulto e idoso mudanças de perspectiva de vida, melhor compreensão das relações estabelecidas no entorno social, favorecendo a ampliação de sua leitura de mundo e a participação em processos sociais.

Nesse sentido, o Curso de Qualificação Profissional em Auxiliar Administrativo integrado com a Educação Básica na modalidade EJA, na Formação Inicial e Continuada com o Ensino Fundamental oferecido pelo Colégio de Aplicação da Universidade Federal de 
Uberlândia configura-se como uma opção de maior respaldo a essa formação, uma vez que incide diretamente nas condições de inserção social, econômica, política e cultural de jovens, adultos e idosos que não concluíram o ensino fundamental. $\mathrm{O}$ curso tem uma abrangência que traz implicações para o mundo do trabalho e, também, a vida doméstica e o cotidiano do aluno, à medida que a formação pretende ampliar o seu olhar, contribuindo, ainda, para a inserção desses jovens e adultos estudantes em uma sociedade digitalizada (COLÉGIO DE APLICAÇÃO DA UNIVERSIDADE FEDERAL DE UBERLÂNDIA, 2015).

\section{1) A língua inglesa na educação de jovens e adultos}

Com o avanço da ciência, o homem tem desenvolvido inúmeras tecnologias que possibilitaram atender às suas necessidades sociais, econômicas, educacionais, resultando na melhoria da qualidade de vida e da comunicação. Diante do atual contexto, a sociedade requer do cidadão uma gama de conhecimentos. A globalização, por sua vez, passa a exigir conexões, parcerias e trabalho conjunto numa perspectiva que supere a passividade do estudante, pois diante de tantos desafios e rápidas transformações, estar "formado para a vida" significa, além de reproduzir dados, adquirir uma atitude permanente de aprendizado.

Nesse sentido, aprender um idioma tornou-se uma necessidade básica para inúmeros profissionais de diversas áreas. O domínio da língua inglesa significa crescimento, desenvolvimento e, acima de tudo, melhores condições para acompanhar as rápidas mudanças que vêm ocorrendo neste novo e tecnológico século. Como sinônimo de sobrevivência e integração global, tal aprendizado abre as portas para o desenvolvimento pessoal, profissional e cultural dos cidadãos.

De acordo com a Lei de Diretrizes e Bases da Educação Nacional (BRASIL, 1996), a aprendizagem de uma Língua Estrangeira, juntamente com a materna, é um direito de todo cidadão, devendo a escola oferecê-la no currículo, como disciplina obrigatória, no ensino fundamental a partir do $6^{\circ}$ ano. Justifica-se a sua inclusão por diversos fatores, como, por exemplo, a possibilidade de o aluno se desenvolver tanto no campo individual, favorecendo as relações interpessoais, quanto no campo profissional, ampliando as oportunidades de inserção no mercado de trabalho e no mundo digital.

A aprendizagem de língua inglesa é, portanto, necessária como instrumento de compreensão do mundo, de inclusão social, além de valorização pessoal. A inclusão social deve atender todos os indivíduos que de alguma forma foram excluídos, compreendendo políticas ou ações que objetivam a inserção dos sujeitos excluídos, preparando a sociedade para o convívio com a diversidade (MANTOAN, 2003). Por meio do estudo da língua inglesa, ampliam-se também as possibilidades de inserção no mundo digital, utilizando os recursos tecnológicos para aprimorar o conhecimento linguístico, ajudando os alunos no desenvolvimento da escrita e da leitura, assim como na compreensão de estruturas linguísticas e discursivas, valorizando o conhecimento prévio dos alunos. 


\section{2) Contextualizando o campo de estudos e as participantes do projeto}

O Colégio de Aplicação da Universidade Federal de Uberlândia compreende a Educação Infantil, o Ensino Fundamental I e II e a Educação de Jovens e Adultos (do $6^{\circ}$ ao $9^{\circ}$ ano do Ensino Fundamental II). Em um universo de aproximadamente 1000 alunos, a modalidade PROEJA representa cerca de 5\% desses estudantes.

O Colégio se localiza em um bairro próximo ao Centro da cidade de Uberlândia, no bairro Aparecida, de fácil localização, o que favorece a frequência de alunos de diferentes bairros da cidade.

O ingresso dos alunos da Educação Infantil e dos Ensinos Fundamental I e II dá-se por sorteio público anual, enquanto o ingresso dos alunos PROEJA se dá por ordem de chegada, já que não há uma procura muito expressiva desse público.

Os alunos PROEJA, a partir da parceria firmada com o IFTM no ano de 2015, recebem, no ingresso ao $8^{\circ}$ ano do ensino fundamental, uma bolsa de estudo do Governo Federal, condicionada à frequência desse aluno ao curso.

Segundo o Projeto Político Pedagógico do PROEJA, as aulas de Língua Estrangeira se restringem ao ensino de Inglês, com duas aulas semanais, de duração de 50 minutos cada, para os alunos do $8^{\circ}$ ano. Para o desenvolvimento das aulas, a escola possui ambientes específicos para o aprendizado de LE, além de laboratório de informática, equipamento audiovisual e multimídia e acesso irrestrito à internet, colaborando dessa forma para o letramento digital em língua inglesa. Portanto, mediante à boa infraestrutura oferecida, o Colégio de Aplicação da Universidade Federal de Uberlândia diferencia-se da maioria das escolas públicas brasileiras.

Em relação à execução do projeto direcionado à elaboração de materiais didáticos para a língua inglesa, foram marcados encontros semanais entre a orientadora e as graduandas, cujo propósito era discutir, com base na literatura acadêmica, a estrutura para a elaboração de material didático-pedagógico e as questões pertinentes ao PROEJA.

$\mathrm{Na}$ primeira etapa do projeto ( $2^{\circ}$ semestre de 2015), as graduandas participaram de algumas aulas no período noturno, a fim de conhecer tanto o alunado do projeto quanto a infraestrutura disponível para o mesmo. Durante as aulas, elas puderam vivenciar aspectos relacionados ao perfil desses alunos, sobretudo no que se refere às relações de ensino e aprendizagem da/com a Língua Estrangeira.

A coordenadora do projeto e professora responsável pelas aulas de língua inglesa possui Doutorado em Linguística Aplicada, além de experiência de mais de 17 anos no ensino de língua inglesa e um pouco mais de 2 anos especificamente com a Educação de Jovens e Adultos. É permanente no quadro docente do Colégio de Aplicação.

As graduandas do Curso de Letras da Universidade Federal de Uberlândia e participantes do projeto dispõem de experiência em outros programas de estágio e bolsas de graduação. A aluna bolsista desse projeto conta com experiência no ensino de língua inglesa desde 1991. Sua prática docente envolveu desde o ensino Fundamental I até a preparação de alunos para o ingresso nos cursos de Mestrado e Doutorado. 
Já a outra discente participante, desde 2012 tem se envolvido em atividades de docência na rede pública e privada de ensino, trabalhando também sob diferentes contextos e com diversos perfis de alunos. Possui experiência como bolsista do Programa Institucional de Bolsas de Iniciação à Docência (PIBID) e trabalha como professora no Programa Idiomas sem Fronteiras (IsF).

\section{3) Contextualizando o público-alvo}

O termo "Educação de Jovens e Adultos", por si só, não define o seu público-alvo, dada a diversidade desse segmento. Conforme análise da diretora do escritório da Organização Internacional do Trabalho (OIT) no Brasil,

As desigualdades de gênero e raça são eixos estruturantes da matriz da desigualdade social no Brasil que, por sua vez, está na raiz da permanência e reprodução das situações de pobreza e exclusão social. Por isso, enfrentar essas desigualdades significa tratar de uma característica estrutural da sociedade brasileira, cuja transformação é imprescindível para a superação dos déficits de trabalho decente atualmente existentes, assim como para o efetivo cumprimento dos Objetivos de Desenvolvimento do Milênio (ABRAMO, 2006, p. 41)

Apesar de esforços para garantir a inclusão de todo cidadão à educação, são necessários anos de trabalho político-pedagógico para que rupturas sejam efetivamente quebradas e barreiras transpostas. No que diz respeito à Educação para Jovens e Adultos, os dados do Relatório Educação Para Todos no Brasil 2000-2015 (MEC, 2014, p. 50) revelam que a participação do sexo feminino vem aumentando a partir de 2008.

Assim, tendo em vista cumprir sua parcela de contribuição nesse processo de inclusão educacional, o PROEJA busca oferecer aos educandos a possibilidade de adquirirem as habilidades de forma significativa, usando situações reais de comunicação, com práticas relacionadas ao cotidiano, trabalhando com materiais didático-pedagógicos relacionados ao mundo do trabalho e integrados ao mundo digital. Tendo isso em vista, a professora e as discentes participantes do projeto não se opuseram em estabelecer o conhecimento prévio desse público-alvo para nortear, com melhor fundamentação, as escolhas didáticopedagógicas no contexto do ensino-aprendizagem da LE.

Considera-se que a definição do perfil do público-alvo precisa ser encarada como um fator primordial no planejamento do curso, das aulas e do material didático-pedagógico a ser implementado, podendo passar por readequações ao longo do tempo. Adquirir uma definição mais completa dos alunos certamente ajudará o professor a estruturar melhor os seus objetivos tanto em relação ao curso, quanto às aulas. Atentar-se para o perfil do aluno pode contribuir sobremaneira para o professor articular as aulas e o material conforme o interesse dos alunos, 
aprofundando saberes e elevando o resultado do aprendizado. Sem conhecer o perfil do seu público-alvo, o professor, como um sujeito de compromisso social e ético, não tem como desenvolver e aperfeiçoar materiais e, portanto, entender as características dos alunos é fundamental para alinhar o desenvolvimento das aulas com a expectativa e a satisfação dos alunos.

Dessa forma, a fim de identificar o perfil dos alunos, suas necessidades, crenças e expectativas em relação à língua inglesa, optou-se pela aplicação de um questionário, composto por 15 questões abertas e fechadas, no intuito de detectar as impressões iniciais dos alunos, antes mesmo de algum conteúdo ser aplicado em sala de aula.

Essa opção metodológica foi considerada a mais adequada para obter informações devido à baixa interferência do pesquisador e a possibilidade de respostas anônimas. $\mathrm{O}$ questionário também se faz acessível por não desencadear custos altos e possibilita sistematizar os resultados obtidos, tornando-se mais fácil automatizar o processo de análise. Além disso, a resposta é imediata, já que todos os alunos respondem ao questionário durante o mesmo intervalo de tempo.

O grupo entrevistado contou com um total de 24 alunos, distribuídos entre 14 homens e 10 mulheres. A partir das respostas do questionário, foi possível traçar o perfil dos alunos ao obter informações pessoais, como: faixa etária, gênero, quantidade de filhos e estado civil. Além disso, também foi possível verificar sua inserção no mercado de trabalho, tempo na função e área de atuação, assim como informações mais aprofundadas sobre a continuidade dos estudos, contato prévio com a língua inglesa e descrição desta experiência (local, duração e impressões). Considerando a idade, há predominância de alunos entre 16 e 30 anos, seguido por alunos na faixa etária de 31 a 45 anos (Gráfico 1).

Gráfico 1: Perfil do alunado entrevistado em relação à distribuição por gênero e faixa etária FONTE: Dados desta pesquisa.

No que diz respeito à constituição familiar, a maior parte dos alunos é casada e, no total, 16 alunos têm filhos (Gráficos 2A e 2B). 
Gráfico 2A: Perfil do alunado entrevistado em relação à sua condição familiar (Status) FONTE: Dados desta pesquisa.

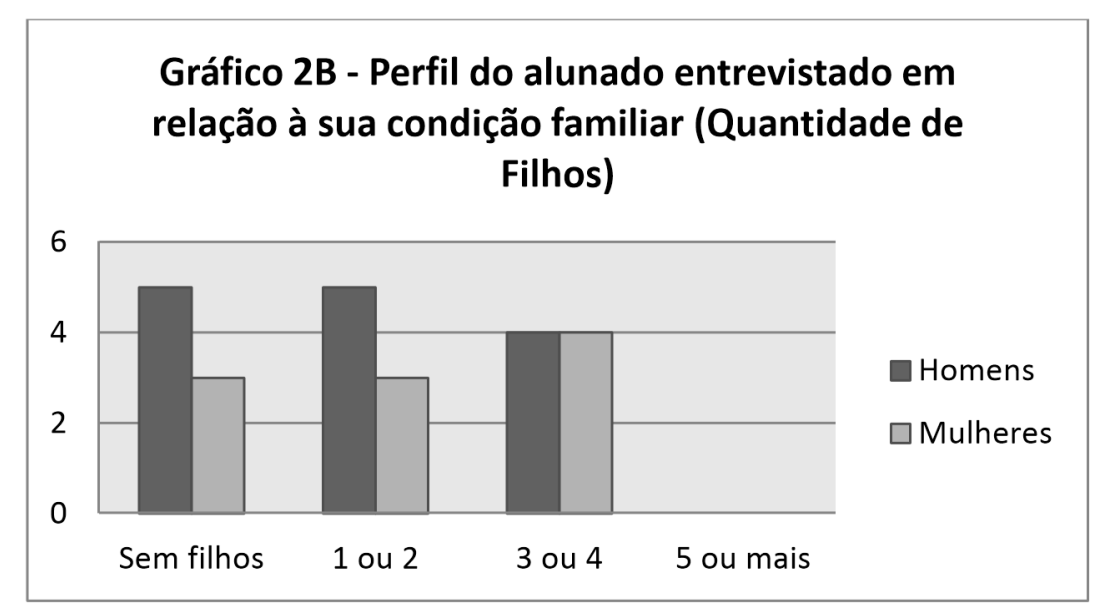

Gráfico 2B: Perfil do alunado entrevistado em relação à sua condição familiar (Quantidade de Filhos) FONTE: Dados desta pesquisa.

Em relação ao trabalho, cerca de 17 alunos estão inseridos no mercado de trabalho, sendo que apenas 1 do sexo masculino e 6 do sexo feminino não trabalham. Em relação à atuação, a área de "Serviços" foi a que teve maior destaque, seguida por "Alimentação". Porém, cerca de 7 pessoas não informaram (Gráfico 3A). Logo, nota-se que a maioria dos alunos é casado(a), com filhos e, atualmente, está inserido(a) no mercado de trabalho (Gráfico 3B). Com base nessas informações é possível dizer que estes alunos possuem consideráveis responsabilidades e um dos seus desafios é conseguir conciliar o tempo entre família, trabalho e escola. 
Gráfico 3A: Perfil do alunado entrevistado em relação à área de atuação

FONTE: Dados desta pesquisa.

Gráfico 3B: Perfil do alunado entrevistado em relação à inserção no mercado de trabalho no momento FONTE: Dados desta pesquisa.

Quanto aos estudos, percebe-se que a maioria (22 alunos) recebe apoio familiar e apresenta interesse em estudar (Gráfico 4A). Observa-se, então, que o cenário é favorável para a aprendizagem, com alunos motivados e dispostos a aprender. Apenas uma aluna não se manifestou a respeito. 
Gráfico 4A: Perfil do alunado entrevistado em relação ao apoio familiar para os estudos FONTE: Dados desta pesquisa.

Além disso, 20 alunos demonstraram interesse em ingressar na universidade (Gráfico 4B), ou seja, pretendem ir além do ensino médio e manter a continuidade dos estudos, confirmando, assim, o seu interesse. Nesse sentido, as respostas apontaram mais de uma possibilidade.

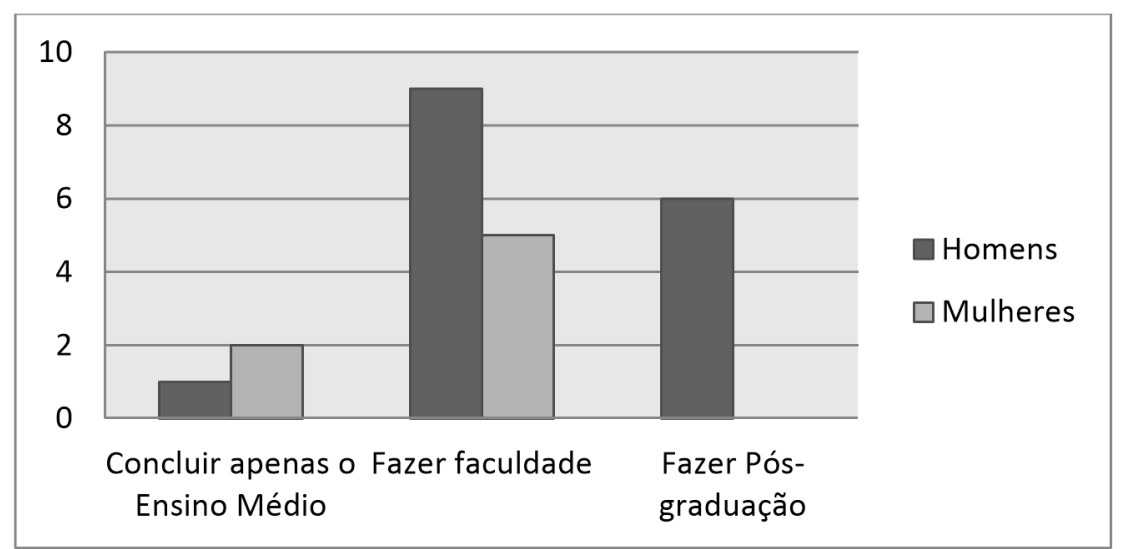

Gráfico 4B: As expectativas em relação à continuidade dos estudos a partir da experiência no PROEJA FONTE: Dados desta pesquisa.

A respeito da língua inglesa, 13 alunos tiveram contato prévio (inclusive 3 deles no Colégio de Aplicação da UFU) e 11 alunos nunca o tiveram (Gráfico 5A). Com isso, para praticamente metade da sala, esta disciplina representa uma experiência nova (Gráfico 5B). Por meio do questionário observa-se que a maioria dos alunos teve experiências positivas em relação ao aprendizado da língua inglesa (Gráfico 5C). 
Gráfico 5A: Local onde se deu esse contato prévio com a língua inglesa FONTE: Dados desta pesquisa.

Gráfico 5B: Contato prévio com a língua inglesa

FONTE: Dados desta pesquisa.

Gráfico 5C: Descrição do tipo de experiência em relação à língua inglesa FONTE: Dados desta pesquisa.

Sobre as expectativas em relação ao ensino de língua inglesa, foram dadas três alternativas no questionário, sendo a mais respondida: "É uma língua não tão difícil, mas que requer prática”, com 20 respondentes (Gráfico 6). Isso demonstra que a grande maioria está 
aberta ao aprendizado da língua, sem resistência. Porém, é importante ressaltar que na prática isso pode não se confirmar.

Gráfico 6: Expectativas em relação ao estudo de língua inglesa FONTE: Dados desta pesquisa.

Ao serem questionados sobre o que pretendem fazer com o conhecimento adquirido do inglês, surgiram as seguintes respostas: saber outro idioma, uso futuro, mercado de trabalho, aprimorar o conhecimento, tecnologia e informática, viajar, adquirir independência e mudar de país (Gráfico 7). Nesse sentido, as respostas apresentaram mais de uma possibilidade.

Desta forma, a representação de língua está fortemente associada à representação de escola, ligada ao futuro, a oportunidades de emprego e de melhorias; há, ainda, o ideal de que a vida em outros países oferece perspectivas melhores. Para estes alunos, a língua representa autonomia e independência, estabelecendo uma nova identidade a este indivíduo. 
Gráfico 7: Ideias expressas a partir do questionamento: "O que você pretende fazer com o conhecimento adquirido na língua inglesa?"

FONTE: Dados desta pesquisa.

\section{4) As bases para a concepção do material didático-pedagógico}

A concepção de qualquer material didático é uma tarefa de extrema complexidade, dada a multiplicidade de fatores que influenciam no processo de elaboração, tais como: o perfil do alunado, a heterogeneidade do conhecimento, os objetivos a serem alcançados, o tempo etc.

No caso da Língua Estrangeira tudo isso ganha contornos ainda mais significativos pelo fato de que, segundo Teixeira e Ribeiro (2012),

O conhecimento de uma Língua Estrangeira vem sendo amplamente difundido e exigido nos mais diversos contextos da contemporaneidade. Nesse sentido, o espaço de aprendizagem desempenha uma nova significação no ensino de Língua Estrangeira, pois sua função está além dos propósitos utilitários da língua, o que possibilita ao aprendiz uma ampla visão da Língua Estrangeira. (TEIXEIRA; RIBEIRO, 2012, p. 185)

Daí a importância da Língua Estrangeira no contexto da Educação de Jovens e Adultos (EJA). Trata-se de democratizar, também, a aquisição de outra língua e torná-la um mecanismo 
de qualificação profissional, expandindo a realidade desse cidadão que, por razões diversas, se afastou da possibilidade de cursar o ensino regular.

Ainda que o projeto, conforme descrito anteriormente, não contemple uma carga horária expandida a todas as séries do ensino fundamental, ficando restrito, neste caso, ao $8^{\circ}$ ano, o simples fato de o aluno se deparar com a Língua Estrangeira, por meio de uma aprendizagem contextualizada em situações reais de uso, possibilitará que ele perceba a importância da mesma para a sua formação enquanto cidadão e, ao mesmo tempo, relevante para sua realidade cotidiana e para a inserção em uma sociedade tida como digital.

Desse modo, ele torna-se capaz de estudar sobre a sua cultura e a do outro com o olhar mais acentuado e crítico, mudando, assim, a visão a respeito do outro e de si mesmo. Como colocado por Moita Lopes (2002), as práticas discursivas

\begin{abstract}
desempenham um papel importante do desenvolvimento de sua conscientização sobre suas identidades e a dos outros. Além disso, tendo-se em mente o fato de que as escolas são, em última análise, instituições socialmente justificáveis como espaços de construção de conhecimento/aprendizagem, pode-se argumentar que os significados gerados em sala de aula têm mais crédito social do que em outros contextos, particularmente devido ao papel da autoridade que os professores desempenham na construção do significado (MOITA LOPES, 2002, p. 37$38)$.
\end{abstract}

Assim, mediante à própria proposta do projeto estabelecido pelo Colégio de Aplicação da Universidade Federal de Uberlândia e o Instituto Federal do Triângulo Mineiro (IFTM), que visa a articulação entre a escola e o mundo do trabalho e a inserção desses jovens, adultos e idosos em uma Era conhecida como Digital, foi possível pensar esse ensino de Língua Estrangeira de maneira mais focada e objetiva, sem se perder na vastidão que tal conhecimento exibe. Foi possível, também, entender o material didático como objeto multidimensional e complexo, que por meio de suas formas e conteúdos revelam expressões ideológicas e concepções de educação.

Conforme demonstrado pela figura 1, definiu-se um fluxograma cujo eixo temático denominado "Sociedade e Tecnologia" se ramificaria em quatro unidades básicas: Who am I? (Quem sou eu?), A Globalization World (Um mundo globalizado), Digital Era (Era Digital) e Jobs (Empregos); sendo que estes pontos de discussão estabelecidos poderiam ser trabalhados de maneira conectada entre si ou em relação às unidades, de acordo com a disponibilidade da carga horária, minimizando, assim, eventuais perdas de aprendizagem. Faz-se importante mencionar que a ideia inicial de construção de um fluxograma se deu no intuito de facilitar a visualização do processo de desenvolvimento do conteúdo a ser trabalhado. 
Figura 1: Fluxograma da proposta para o Ensino de língua inglesa no PROEJA.

A ideia dessa proposta é fazer com que os assuntos sejam sempre recapitulados ao longo do semestre, demonstrem a sua importância dentro do contexto de aprendizagem, e que as atividades propostas visem a otimização do tempo de aula e o conforto dos alunos na sua realização. Isso significa que, pensando na diversidade de perfil do alunado que participa da EJA, oferecer ao aluno a fundamentação teórica e os exercícios já impressos reduz a dificuldade deles em relação à estrutura linguística do inglês (como por exemplo, a presença das letras K, W e Y, não tão comuns na língua portuguesa).

Por ser um curso pensado na/para Era Digital, parte desse planejamento se dá em parceria com outros conteúdos curriculares, a partir da elaboração de um Projeto Multidisciplinar para o $8^{\circ}$ ano, intitulado: "Plano de RH", cujo eixo integrador denomina-se: Sociedade e Tecnologia e consiste na criação de três empresas fictícias em diferentes ramos de atuação. Os grupos, de até 5 alunos, devem elaborar um trabalho escrito e uma apresentação oral. Para a parte escrita, devem realizar pequena pesquisa acerca do ramo de atuação da empresa a ser criada, descrevendo o plano de cargos e salários, determinando a incidência de impostos e encargos para uma empresa e, ainda, descrevendo os requisitos e perfis para o processo seletivo de um cargo de auxiliar administrativo. Em seguida, espera-se que os alunos montem um requerimento (de acordo com as aulas de Comunicação e redação empresarial), solicitando a abertura de uma nova vaga. Para a apresentação oral, os slides devem ser preparados em PowerPoint para todos os itens desenvolvidos.

No que se refere ao conteúdo de língua inglesa, os alunos devem produzir uma carta de apresentação de um funcionário de um setor que pretende transferência para outro, contendo uma breve descrição das principais experiências e competências/habilidades pessoais e profissionais. Durante todo o semestre, as aulas de língua inglesa visam capacitar o aluno para 
a escrita da carta de apresentação, com a introdução de vocabulário e estruturas linguísticas direcionadas à confecção da carta.

Com o trabalho multidisciplinar, o aluno, além de praticar, aprende a escolher instrumentos tecnológicos, tais como: editores de texto, sites de tradução, navegadores etc., cujos vocabulários, estruturas linguísticas e morfológicas se fazem a partir da língua inglesa.

\section{Considerações finais}

É possível dizer, então, que o curso de língua inglesa no PROEJA do Colégio de Aplicação da UFU conseguiu consolidar o entendimento da língua como uma prática social heterogênea, contextualizada e cultural, possibilitando conduzir os alunos a perceberem seu papel ativo na sociedade e a legitimarem experiências de cidadania. Tal entendimento parte de uma concepção de língua como discurso, o que significa pensarmos as práticas da linguagem "como práticas de (re) significarmos o mundo e o que acontece em nossa volta, a forma como percebemos a realidade. Uma mudança em nossas práticas discursivas nos leva a uma mudança de identidade e a diferentes leituras do mundo" (JORDÃO; FOGAÇA, 2007, p. 87).

Esse projeto foi extremamente proveitoso e válido, ao proporcionar às graduandas a prática de desenvolver materiais didático-pedagógicos para a modalidade EJA, uma vez que se sentem mais preparadas para a execução desse tipo de atividade e para a sua futura prática em sala de aula. Nesse sentido, faz-se importante destacar que a equipe formada teve a felicidade de estar na mesma sintonia, entendendo a dinâmica do processo sob o mesmo enfoque. Houve um constante compartilhar de criatividade, de conhecimentos, de experiências; embora, sempre cientes de que o desenvolvimento de um projeto assim não deixa de ser um misto de desafio e prazer. Tudo precisou ser pensado e repensado muitas vezes, buscando analisar o máximo de variáveis possíveis para tornar cada atividade exequível e capaz de gerar o máximo de resultados positivos de aprendizagem aos alunos do PROEJA.

Muito embora este seja um projeto pontual, faz-se importante ressaltar que sua contribuição está alinhada às expectativas previstas na Declaração Universal dos Direitos Linguísticos (UNESCO, 1996), sobretudo em sua seção II, artigos 23 a 30. Trata-se de compreender que o ensino deve manter ativa a necessidade de lutar pelo pluralismo cultural e linguístico, bem como garantir um desenvolvimento duradouro e equitativo para todas as pessoas, favorecendo um quadro de organização política da diversidade linguística baseado no respeito, na convivência e no benefício recíproco.

Afinal, em pleno século XXI, não há como negar que o processo de globalização da economia e seus desdobramentos no campo da informação, da comunicação e da cultura afetam as relações humanas e suas formas de interação. 


\section{Referências}

ABRAMO, L. Desigualdades de gênero e raça no mercado de trabalho brasileiro. Cienc. Cult., São Paulo, v. 58, n. 4, 2006, p. 40-41. Disponível em $<$ http://cienciaecultura.bvs.br/scielo.php?pid=S0009-

67252006000400020\&script=sci_arttext>. Acesso em: 01 mar. 2016.

BRASIL. Lei $n^{\circ}$ 9.394, 20 de dezembro de 1996. Estabelece as diretrizes e bases da educação nacional. Diário Oficial [da] República Federativa do Brasil, Brasília, DF, 23 dez. 1996. MINISTÉRIO DA EDUCAÇÃO. PROEJA Formação Inicial e Continuada Ensino Fundamental - PROEJA/FIC/Ensino Fundamental. Documento Base, 2007. Disponível em <http://portal.mec.gov.br/setec/arquivos/pdf2/proeja_fundamental_ok.pdf>. Acesso em: 07 out. 2016.

20002015. Disponível em

MINISTÉRIO DA EDUCAÇÃO. Relatório Educação para todos no Brasil $<$ http://portal.mec.gov.br/index.php?option=com_docman\&view=download\&alias=15774eptrelatorio-06062014\&Itemid=30192>. Acesso em: 01 mar. 2016.

COLÉGIO DE APLICAÇÃO DA UNIVERSIDADE FEDERAL DE UBERLÂNDIA. Projeto Pedagógico do Curso Qualificação Profissional em Auxiliar Administrativo Integrado à Educação de Jovens e Adultos do Ensino Fundamental. Uberlândia, 2015.

FINARDI, K.; PREBIANCA,G.; MOOM, C. Tecnologia na Educação: o caso da Internet e do Inglês como Linguagens de Inclusão. Revista Cadernos do IL, v. 46, p. 193-208, 2013.

FREIRE, P. Pedagogia da autonomia: saberes necessários à prática educativa. São Paulo: Paz e Terra, 1997.

JORDÃO, C. M.; FOGAÇA, F. C. Ensino de inglês, letramento crítico e cidadania: um triângulo amoroso bem-sucedido. Línguas e Letras, 2007, v. 8, n. 14, p. 79 - 105. 
MANTOAN, M. T. E. Inclusão escolar: o que é? por quê? como fazer?. São Paulo: Moderna, 2003.

MOITA LOPES, L. P da. Identidades Fragmentadas: a construção discursiva de raça, gênero e sexualidade em sala de aula. Campinas, SP: Mercado de Letras, 2002.

ORGANIZAÇÃO DAS NAÇÕES UNIDAS PARA A EDUCAÇÃO, A CIÊNCIA E A CULTURA (UNESCO). Universal Declaration on Linguistic Rights. Disponível em $<$ http://www.unesco.org/cpp/uk/declarations/linguistic.pdf>. Acesso em: 01 maio 2016.

SILVA, C. P. et al. Educação Profissionalizante e inclusão social na Escola Municipal de Aprendizagem Industrial (EMAI). Simpósio de Ensino Pesquisa e Extensão. Santa Maria, 2012. Disponível em <http://www.unifra.br/eventos/sepe2012/Trabalhos/5301.pdf >. Acesso em: 10 maio 2016.

TEIXEIRA, C. S.; RIBEIRO, M. A. A. Ensino de Língua Estrangeira: concepções de Língua, Cultura e Identidade no contexto do Ensino/Aprendizagem. Linha d'Água, São Paulo, n. 25 (1), p. 183-201, 2012. Disponível em

<http://www.revistas.usp.br/linhadagua/article/view/37372>. Acesso em: 29 out. 2015. 